\title{
Food for Thought ... on Alternative Methods for Chemical Safety Testing
}

\author{
Thomas Hartung \\ CAAT, Johns Hopkins University, Bloomberg School of Public Health, Baltimore, US, and CAAT-EU, University of \\ Konstanz, Germany
}

About 70 million chemicals have been synthesized, as registered in Chemical Abstracts Service. It is not really clear how many are found in consumer products and the environment. Why not? First, because registrations are only required for certain production volumes. Second, no organization or entity tracks increases in production volumes. I am not aware, for example, of very many new chemicals (in Europe, those notified after September 1981) that have been reregistered and subjected to additional testing demands due to higher production volume; this might be a reason why practically all new chemicals (registered from 1981-2006) have been pre-registered again for $\mathrm{REACH}$, from which they are exempted in principle. Similarly, no procedures exist to track when thresholds for registration are exceeded on a European level by different manufacturers combined, when originally only tiny amounts were produced. In Europe, until 2007, the threshold for notification was $100 \mathrm{~kg}$ (now 1 ton) per year, which resulted in about 300 files per year. In the smaller US chemical industry the number of premarketing notifications is about 2,000 per year, giving us an idea about how few chemicals are accurately monitored in Europe. Third, requirements for registration differ considerably. Many chemicals enter our markets as components of products. Who registers when a sport shoe manufactured somewhere in Asia is imported and its fashionable, decorative glitter is produced by chemicals? Sure customs (and prior to REACH directive 67/548/EEC) ask for documentation but in practice many importers are not aware of every component of the product. Fourth, many additional compounds, especially in the environment, are decomposition and reaction products. Fifth, things get really difficult when we also have to think of different formulations as particles. It is well known that nanoparticles (i.e. chemical particles typically between 1 and $100 \mathrm{~nm}$ ) change their behavior depending on size and shape. A whole new field of nanotoxicology is emerging, which will be the subject of a future article in this series. But effects relevant to toxicity also occur on a larger scale. We know that both crystal sizes and shapes of drugs affect bioavailability and side-effects. A reasonable estimate is that people are exposed to about 100,000 relevant synthetic chemicals $(84,000$ are listed in the cumulative US TSCA inventory, 100,000 in the EU EINECS inventory) in contrast to the 5,000 to 10,000 for which actually (widely varying in depth) safety assessments exist. The knowledge gap is, from this view, tremendous. This gap is even deeper if we consider the effect of chemicals in mixtures, where synergies may occur as recently addressed by the EU Council of Environment Ministers (http:// register.consilium.europa.eu/pdf/en/09/st17/st17820.en09.pdf).
However, we are most likely exposed to an even larger number of chemicals, given all the naturally occurring sources. I was once very much impressed when I learned that a plant extract used as a drug can contain 40,000 substances. With regard to possible toxic properties, there is no difference between a substance produced by chemical synthesis or by the metabolism of an organism - on the contrary, some of the most toxic substances are "natural" because evolution has optimized these poisons. Similarly, there are byproducts from chemical synthesis to be considered. Petrochemicals fall somewhere in-between, as they are very heterogeneous as natural products to start with and fractionation will always remain partial.

\section{Consideration 1: Not every toxic chemical we can measure in our food, consumer products, bodies, or in the environment is relevant}

Paracelsus (Phillip von Hohenheim, 1493-1541) is often considered the first toxicologist. His most famous quote is: "All things are poison and nothing is without poison, only the dose permits something not to be poisonous." (Alle Ding' sind Gift, und nichts ohn' Gift; allein die Dosis macht, daß ein Ding kein Gift ist.) Today we say it more succinctly: The dose makes the poison. While Paracelsus is rightly credited for this (and we need to expand on this here), we might blame him for the other part of the quote: "All things are poison." No, most things are not poison. There are many things you can give to people and they will never be poisoned. Sure, you can be killed by distilled water or kitchen salt, but bread, butter... More than $90 \%$ of chemicals applied at $2 \mathrm{~g}$ per $\mathrm{kg}$ do not kill rats - we consider them non-toxic. Paracelsus has been the forerunner of a view that chemicals are bad. But we have tripled life expectancy since synthetic substances were introduced into our daily lives on large scale. There are very few cancer types, for example, that have increased when corrected for age, i.e. accounting for the fact that we survive today long enough to get the cancer.

Still, we are uneasy about dangerous substances found in our environment, our food, or our bodies. One of the most effective press releases of the European Commission took place when EU Environment Commissioner Margot Wallström had her blood tested for the presence of some toxins (European Commission, 2003), effectively timed for one week after the REACH draft was handed to the European Parliament and Council. The fact that 28 of 77 toxins tested for were found shows only the sensi- 
tivity of our current analytical methods. If we were to increase the sensitivity of our measurements to one molecule per liter, we would likely find everything in everything. However, at a certain point, i.e. below certain concentrations, it does not matter anymore. Almost every toxic effect has a threshold, at which hazards can reasonably be expected to manifest. This has been formalized as thresholds of toxicological concern (Kroes et al., 2005; Munro et al., 2008), a very effective way to deprioritize those substances where exposure versus likelihood of effect is negligible. It is argued that no such thresholds exist for carcinogens, with the belief that even a single molecule can result in a mutation and thus result in cancer. These genotoxic chemicals, however, can be identified in vitro without threshold assumptions (reducing enormously the number of non-threshold assessments), but then resulting in many false positives. Aside from that, we now understand that multiple events are necessary to result in cancer. We should view this as a lottery. A single lottery ticket is very unlikely to win, and ignorance of this fact has made many people rich - mainly lottery organizers. So even if there is no absolute threshold, there is one where the risk becomes ridiculously small. A practical threshold often used is one death in one million people exposed per year, but this level is set politically and often depends on how affordable it is to lower the risks relative to the benefits. Most importantly, this decision should be guided by absolute not relative risk. If something is rare, even doubling the risk (100\% increase!) will be rare.

Detectable levels must be seen relative to such thresholds of concern. A good example of this is acrylamide: the detection of low levels in food as a natural part of the baking process (everything that browns, like cookies or french fries, contains acrylamide) was linked to the high-dose risks of the pure substance, which was entered into the REACH list of substances of very high concern (SVHC). The public outcry in 2002 was enormous, when reports from Sweden indicated the presence of this dangerous chemical in our food. However, the safety factor for its neurotoxic effects is 200 and for cancer 300 (Parzefall, 2008); notably, the cancers found in rodents are not considered relevant to humans (Shipp et al., 2006).

\section{Consideration 2: Toxicology was not developed for chemicals and certainly not for testing existing high-production volume chemicals}

One of the key lessons learned in validation is that a method must have a clearly defined purpose before we can consider applying and evaluating it. Most of the methods we have were introduced for the safety evaluation of drugs under development. These are substances meant to be bioavailable and have biological effects. Typically, there are also a number of structural variants from which to choose the lead compound in case a toxicological problem develops. At this stage in drug development, most importantly, there is neither experience with human exposure nor a market value, other than the development costs.

So, does a toxicology designed for pharmaceutical substances under development, used to some extent for new low production volume chemicals over the last decades, suit us for the assessment of existing high production volume chemicals? Not without, at minimum, an assessment of its suitability. We need to determine how cautious we want to be. The hassle involved in restricting the use of or substituting for substances with complex use scenarios may be considerable and should be undertaken only if well warranted. We also need to ask whether the methods are applicable to the type of substances. We might think that we have a lot of experience due to the Dangerous Substance Directive, which was in effect from 1981 until it was replaced by REACH, or the parallel Toxic Substance Control Act in the US. For many tests - though prescribed for three decades for new chemicals - we have, in fact, minimal experience with industrial chemicals, because they were not triggered for the relatively small production volumes of new chemicals. We found 14 cancer bioassays and 46 two-generation studies in 28 years for about 4,500 notifications. It is easy to accept major testing demands for high production volume chemicals if they are never applied. Now, thirty years later, it is obviously difficult to complain that they were implemented in the first place.

\section{Consideration 3: REACH - The opposite of well-done is well-meant}

This is a translation of the notion by Karl Krauss "Das Gegenteil von gut ist gut gemeint." REACH is well-meant but it is not well-done in all aspects. It is well-meant because it rightly addresses the knowledge gap for the safety of chemicals. The vast majority of commerce with chemicals is done with old chemicals that have never undergone risk assessments at today's standards. However, I have substantial concerns about how the new legislation approaches the problem. Before addressing those concerns, I should clarify that I have contributed to drafting the legislation and thus have to take some responsibility where it falls short: I joined the European Commission (EC) in October 2002, exactly one year before the EC handed the Commission proposal for REACH to Parliament and Council and left it to the political process. As a pharmacologist of infectious diseases, I was not at all familiar with chemical safety assessments and the REACH discussion, but we organized with the team at ECVAM and a lot of help from outside colleagues the respective comments to the emerging legislative draft. In retrospect, however, we restricted ourselves far too much to alternative methods and how they are included. This is, on the one hand, a success story for alternative methods (from not being mentioned in the White Paper in 2001 to becoming a principal goal of REACH in Article 1; see Box 1) but on the other hand it misses the larger picture. I have to admit that it took me years to understand that regulatory toxicology is a quilt - a patchwork of testing demands, where every scandal has added a patch usually representing a quick fix of the problem. Introducing alternative methods means exchanging one patch for another. This does not make the patch better (except for animal welfare aspects) since we validate against the original patch, but, more importantly, it does not allow changing the design of the quilt. Our toxicology is about as old as London's Heathrow Airport (built in World 
War I) and it looks very much like it, with the continuous adding and redoing of its parts. It is very different from something we would design today from scratch.

We typically forget the compromises made when introducing the quick fixes in response to scandals. And then we learn from the experience of using them, or so we believe. But as Petr Skrabanek and James McCormick masterfully phrased it: "Learning from experience may be nothing more than learning to make the same mistakes with increasing confidence." (Skrabanek and McCormick, 1998). I love the quote and recently received a wonderful example proving this in the introduction of toxicological tests from George Daston at P\&G. He shared with us a letter written by the FDA to the company in 1966 introducing the two-generation reproductive toxicity test following the thalidomide (Contergan ${ }^{\mathrm{TM}}$ ) scandal. At the end it reads: "It must be realized that even these improved guidelines reflect merely the 'state of the art' at the present time, and undoubtedly further modifications will be needed in the future as additional knowledge is developed in this area." This review and amendment has never taken place, and today the assay is defended and considered the gold standard (Gilbert, 2010).

So where are the problems of REACH? First, it is highly complex (Fig. 1,2) and becoming much bigger than anticipated. We opened this discussion in the last two issues of this journal (Rovida and Hartung, 2009; Hartung and Rovida, 2009a) and others (Hartung and Rovida, 2009b), generating enormous public interest. We will not reenter the discussion here, but at the end of the year, when the first notification deadline for REACH arrives, we will start to see how accurate our estimates were. The real discussion, however, is not about costs and animal numbers - it is about how these indicators reflect testing capacities.

Even more important is the fact that toxicological methods were not tailored for this purpose. Taking a precautionary approach for the most valuable chemicals we have is unforgivable.
The chemical industry, with $€ 563$ billion turnover per year in Europe (one third of the world market) (Bottini and Hartung, 2009), does not really fear a program that costs $€ 10$ billion over 15 years. Nobody wants to sell dangerous goods, thus there is no resistance to that aspect of REACH. It is good that we identified asbestos as a problem (Selikoff, 1990) (by the way, not with standard testing in rodent models (Maxim and McConnell, 2001)) and largely removed it from our lives. We also have seen, however, how difficult it is to deal with the replacement of a high production volume substance. But the chemical industry should be afraid of the wrong decisions and their costs. Now we are going to use routine testing - up to 14 animal tests and costs of $€ 5$ million per chemical - for our high production volume chemicals. My (educated) guess is that at least ten times more false than correct positive findings are obtained from the cancer bioassay and reproductive toxicity tests. If the two were independent hazards, which they are not, and all substances would be tested, which they are not, we would have to consider about $90 \%$ of the high production volume chemicals to be labeled for these hazards. However, some basic principles, such as bioavailability and reactivity, apply to both hazards and make it more likely that "only" two-thirds of the substances will be flagged for carcinogenicity or reproductive toxicity. The fact that a very careful guidance on the cancer bioassay is given in the EChA guidance to industry, i.e. to use the animal test only as a last resort, will in practice reduce this to some extent. Still, no one has a plan for handling the possible false-positive results. Further testing? What can overrule an animal experiment that is considered definitive - repeated testing, mode of action studies or using other species? The answer is: human relevance based on mode of action studies, but this will result in significantly more testing.

Another important question is, how do we communicate to consumers that such results do not necessarily mean that they have been exposed to life-threatening chemicals? What liabili-

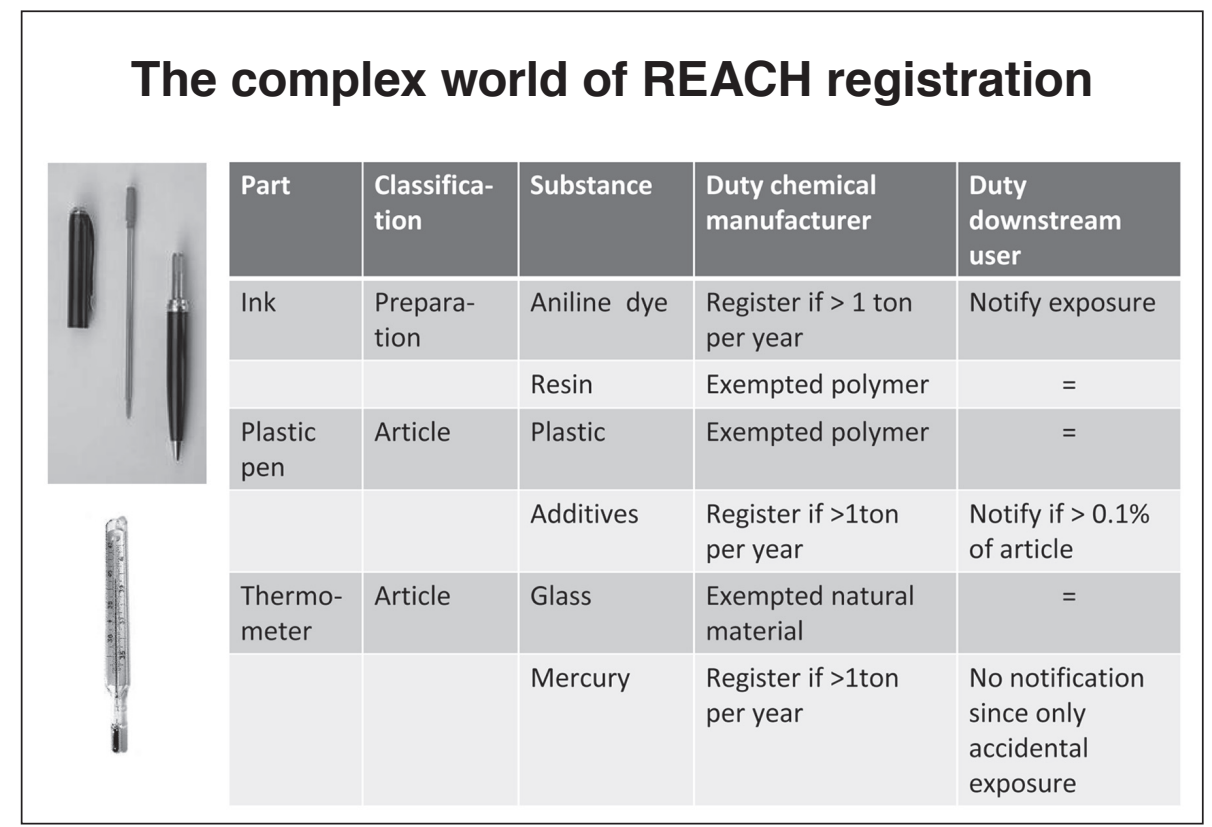

Fig. 1: The complex world of REACH registration

The example of a roller pen and a thermometer is taken to illustrate the duties for registration and notification of downstream use for exposure lifecycle assessment. Please note that the composition of the products is idealized for instructive purposes. The author is also aware of the marketing ban for mercury thermometers in the EU, which were used as educative example here. 
ties are created, e.g. if "suspect" products are not withdrawn immediately? Labeling excessively substances as toxic also will get people used to the label, so they will pay less attention to the really dangerous substances.

A completely different problem with REACH is that we err on the wrong side, especially for new chemicals ("non-phase-in substances"). Obviously, the feeling was that we have so many low volume chemicals that we should tread lightly. Animal testing was reduced in two ways: first, the starting threshold was raised from $100 \mathrm{~kg}$ to 1 ton per year of commerce. I would roughly estimate that this brings down the number of substances to be notified from 300 per year to less than 50; though we do not know yet which additional testing demands the new European Regulation on classification, labeling, and packaging of substances and mixtures (CLP Regulation (European Commission, EC) No 1272/2008) will create. Second, the number of tests was reduced to acute toxicity and the local lymph node assay for skin sensitization only and, most importantly, starting repeat dose testing only at 10 tons or more (omission of eye irritation and skin irritation is more an adaptation to technical progress). Mutagenicity testing is often added, since the battery of in vitro tests is notorious for (false) positive results, which then trigger "further mutagenicity testing" in vivo. Using the assumptions of our earlier report (Rovida and Hartung, 2009) and assuming that $95 \%$ of new chemicals constitute 1-10 tons and $5 \%$ 10-100 tons, the result for annually 50 chemicals is about 3,400 animals total per year. This has to be contrasted with 100160,000 animals used for testing new chemicals per year in the past, which might be considered a nice reduction $(97 \%$ fewer animals for new chemicals testing), but, in fact, shows how little we will know about the toxic profiles of new substances in the future (Greim et al., 2006). Repeated dose systemic toxicity testing is simply the cornerstone of current risk assessment and abandoning it for most substances without a new test paradigm is difficult to understand. However, it has to be acknowledged that many low production volume substances will have exposure profiles that are negligible for the general population. So it is more a demand of worker protection.

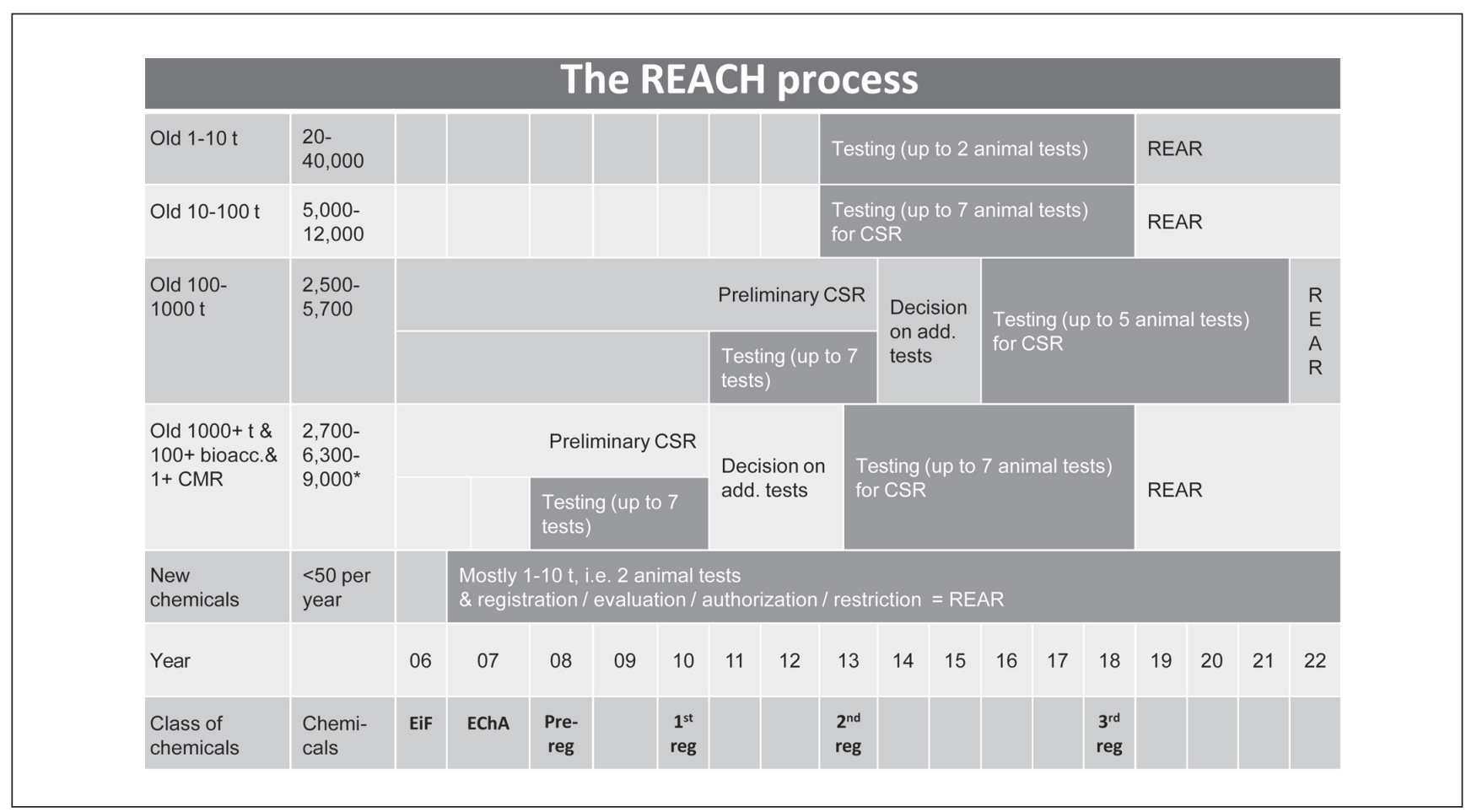

Fig. 2: The REACH process

The timelines of REACH from 2006 to 2022 are displayed for the different classes of chemicals. Key dates are indicated: EiF = Entry into Force 6'06, start of EChA in 6'07, end of pre-registration 12'08 as well as the registration deadlines in 12'10, 12'13 and 12'18. New chemicals ("non-phase-in substances") are regulated from 6'07 and undergo the same registration / evaluation / authorization / restriction (REAR) process supposedly continuing beyond 2022. Numbers of chemicals per class of old ("existing") chemicals are given as the original European Commission estimates and our corrected estimates (Rovida and Hartung, 2009); * refers to a recent EChA estimate including bioaccumulating and persistent chemicals (bioacc.), supposed carcinogenic / mutagenic / reproductive toxic (CMR) chemicals and intermediates. The number of new chemicals at $1+$ tons is a personal estimate given that about 300 chemicals were registered annually at $100+\mathrm{kg}$ in recent years. CSR is the Chemical Safety Report. The preliminary CSR can be handed in any time but for this graph only the deadline is indicated. The agency has two years after submission to decide on proposed testing plans for 100-1000 and 1000+ chemicals. Testing is idealized as a six year period given that the longest test, i.e. the cancer bioassay, requires about four years for execution; this does not take available test capacities into account. 
It is interesting to see this predicted in the timelines (Fig. 1): REACH entered into force $(\mathrm{EiF})$ in mid-2006 with the agency starting in mid-2007. Since then all new chemicals are under continuous testing and registration / evaluation / authorization / restriction (REAR), which means within 6 months after manufacturing they must be fully registered. Since EiF companies were expected to work on the preliminary Chemical Safety Report (CSR) and pre-register by December 2008. The preliminary CSR is due by December 2010, if their substances fall under the first class of REACH, i.e. the 1000+ tonnage range plus $100+$ tonnage range for bioaccumulating and persistent chemicals, as well as $1+$ tonnage range for supposed carcinogenic/mutagenic/ reproductive toxicants (CMR). The law requires that consortia to share in vivo data (SIEF, i.e. a Substance Information Exchange Forum) are formed mainly to avoid duplicate testing. In principle, the preliminary Chemical Safety Reports (CSR) can be submitted any time now, but in practical terms most will be submitted toward the deadlines, i.e. December 2010. The CSR will identify data gaps and suggest the testing strategy, i.e. mainly the necessary animal tests. The agency then has two years, including public consultation, to decide on the testing strategy. Then animal testing starts with up to 14 in vivo tests per substance; it is impossible to foresee how long this will take because of limited testing capacities. Ideally, we can assume a six-year period, given that planning and execution of the longest test, the cancer bioassay, in practice lasts three to four years (two years of animal treatment, one year for histopathology, up

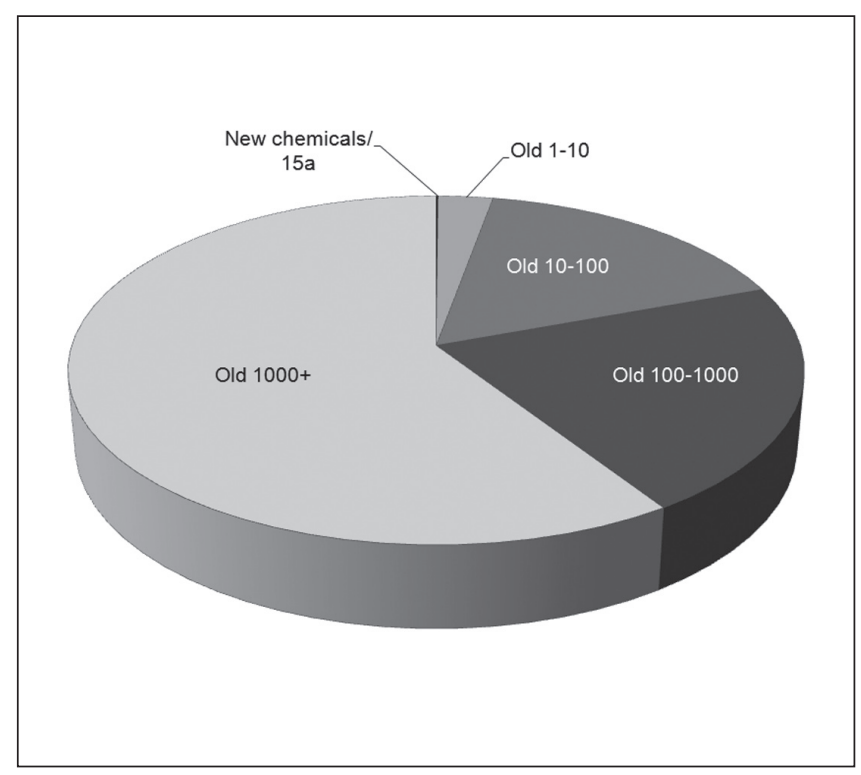

Fig. 3: Animal numbers REACH: 54 million

Data from (Rovida and Hartung, 2009) were compiled. Notably, official numbers are about five time lower but largely reflecting the distribution. The concomitant animal use for new chemicals was added assuming 50 chemicals per year, $95 \%$ of them in the $1-10$ ton range and $5 \%$ in the $10-100$ ton range. This results in 3,400 animals per year and even when adding up over the 15 years to 51,000 are hardly visible in the graph. to one year for preparation and reporting) and time is needed to compile the final CSR to regulatory REAR.

The second deadline for the 100-1000 tonnage range is in December 2013. The whole process is shifted by 3 years, and test requirements are somewhat lower (up to 12 animal tests).

The 10-100 tonnage chemicals have to produce a CSR instantly with a deadline of December 2018 without a preliminary CSR. It can be assumed that testing (up to 7 animal tests) will take place in the six years before this deadline. The 1-10 tonnage chemicals do not need a CSR and are notified with up to two animal tests with the same deadline of December 2018.

Ideally, animal testing for existing chemicals would start in 2011 and end around 2021. If we use our estimates (Rovida and Hartung, 2009) of animal numbers (Fig. 3):

- 1-10 tons: 1.5 million

- 10-100 tons: 9 million

- 100-1000 tons: 11.6 million

- 1000+ tons: 32.2 million

These idealized timelines (assuming equal spread over the six-year testing intervals) will result in the timeline represented in Figure 4. This suggests a sudden increase of approximately 5 million animals next year, a peak of around 9 million from 2014-2016, and a steep decline toward 2021. It is always good to compare estimates to the current annual use for all purposes of animals in Europe, which is about 11 million per year. Those who prefer not to follow our increased estimates can roughly divide by 5 to arrive at the numbers estimated by EChA. This illustrates quite clearly that REACH will not be finalized in one decade, since the testing capacities are impossible and unrealistic. To increase twentyfold for some years (EChA) to a hundredfold (our estimates) testing of chemicals in animals is simply not possible. It will take longer, and that is good - there is no reason to assume that we will have substantially more alternative approaches in a few years, as efforts to develop new approaches (not including validation) for consumers, i.e. reproductive toxicity testing and repeated dose testing, have just ceased (ReProTect (Hareng et al., 2005) ended 2009) or are only starting (EC/COLIPA call 2010), respectively. For validation and from the in silico field no answers are in sight. (Sorry for the repetition.) It is difficult to understand why investment in these areas is so limited, coming only from the cosmetic area, particularly in light of the current $€ 50$ million call. So we can be happy for such delays, if they allow a move toward new approaches, but this requires credible investments. Too often we behave like the man in Figure 5, who applies the tools he has even though the goal requires different tools.

We should also be clear that when REACH ends, the toxicology of industrial chemicals does not. Besides emerging new chemicals, increased production volumes and concerns of very low production volume chemicals, there are concerns about nanoparticles with novel (toxic) properties, new health effects (endocrine disruption, developmental neurotoxicity such as autism, respiratory sensitization, childhood asthma etc.), and the question of mixtures. And, as we should not forget, animal models miss some relevant human toxicities (Silbergeld, 2004) - for example, there is no animal model of cigarette smokeinduced lung cancer, no rodent leukemia by benzene, and no 
genetic mutations in animals by arsenic. This shows that we cannot close the books on a given chemical after our chemical safety reports are filed.

\section{Consideration 4: The upside of REACH is the broad introduction of Integrated Testing Strategies}

Despite the fact that REACH finally tackles the problem of existing chemicals, the most important advancement of the legislation is to change risk assessment from a laundry list of mostly animal tests to integrated testing strategies (ITS - I prefer the term 'integrated' very much to 'intelligent', which is often used as synonym, but fortunately results in the same abbreviation). We have discussed the problem of "one size fits all" types of animal tests earlier in this series (Hartung, 2008a). REACH requests the broad use of computational (Hartung and Hoffmann, 2009) and in vitro methods (Hartung, 2007b), as well as any type of existing data. This alone is a major advancement as a call to embrace scientific progress in a field, which is cemented in quasi-eternal test guidelines. But REACH starts one step earlier - it requests the use of all reasonably available existing information first. For the use of such existing data quality assurance is of critical importance, as we have discussed (Hartung, 2009c, 2010), serving as an important first step in the development of a scoring tool (Schneider et al., 2009). It is of critical importance that this development is furthered and expanded to in silico and ecotoxicological studies, for example.

I am concerned about the different treatment of in silico and in vitro methods in REACH (Hartung and Hoffmann, 2009), especially, that validation is not explicitly required and the use for identification of non-toxic substances is much easier. This can only be understood by the fact that some of the individuals drafting the legislation came from this background. While in vitro methods (at least the traditional low-tech ones) have reached a status of consolidation (and perhaps even saturation), the in silico tools are still undergoing dramatic developments. The (Q)SAR tools, which derive correlations based on physicochemical descriptors and which were in vogue at the time of drafting the legislation, have in general not fulfilled expectations (Johnson, 2008; Maggiora, 2006). They are now increasingly substituted by mode-of-action-based systems, systems mining existing literature, and combinations with biological data in systems toxicology approaches. This reflects normal scientific development in a vibrant area, but also shows how dangerous it can be when legislation is tailored toward particular methodologies. It would be much better not to prescribe a method but an information requirement; REACH does this not only for (Q) SAR but also for in vivo tests. While we might be happy that it prescribes the local lymph node assay, which strongly increases the pressure to overcome the older guinea pig tests it refines, the explicit mentioning of the two-generation study has lead to objections by EChA and recommendations to adopt the extendedone-generation test instead (Gilbert, 2010).

In principle, however, the legislation is open for change and new methods. Moving from a method annex (the famous Annex V of the European Dangerous Substance Directive) to guidance published by the agency is an attempt to allow faster adaptation of scientific progress, primarily intended for the incorporation of new alternative methods. This will be in the future less frequently a one-to-one substitute, but implementation of integrated testing strategies using the different approaches, with hopefully fewer (refined) in vivo approaches. This is not explicitly foreseen in the legislation but was the clear result of the REACH Implementation Projects developing the guidance for industry testing strategies. So far, the guidance has promoted mainly tiered testing strategies, i.e. a very simple form of sequential use of approaches depending on availability and applicability. It is easy to predict that truly integrated strategies have much more to offer. For example, modeling of in vivo kinetics (ADME-adsorption, distribution, metabolism and excretion) may be integrated with in vitro tests, they can include decision

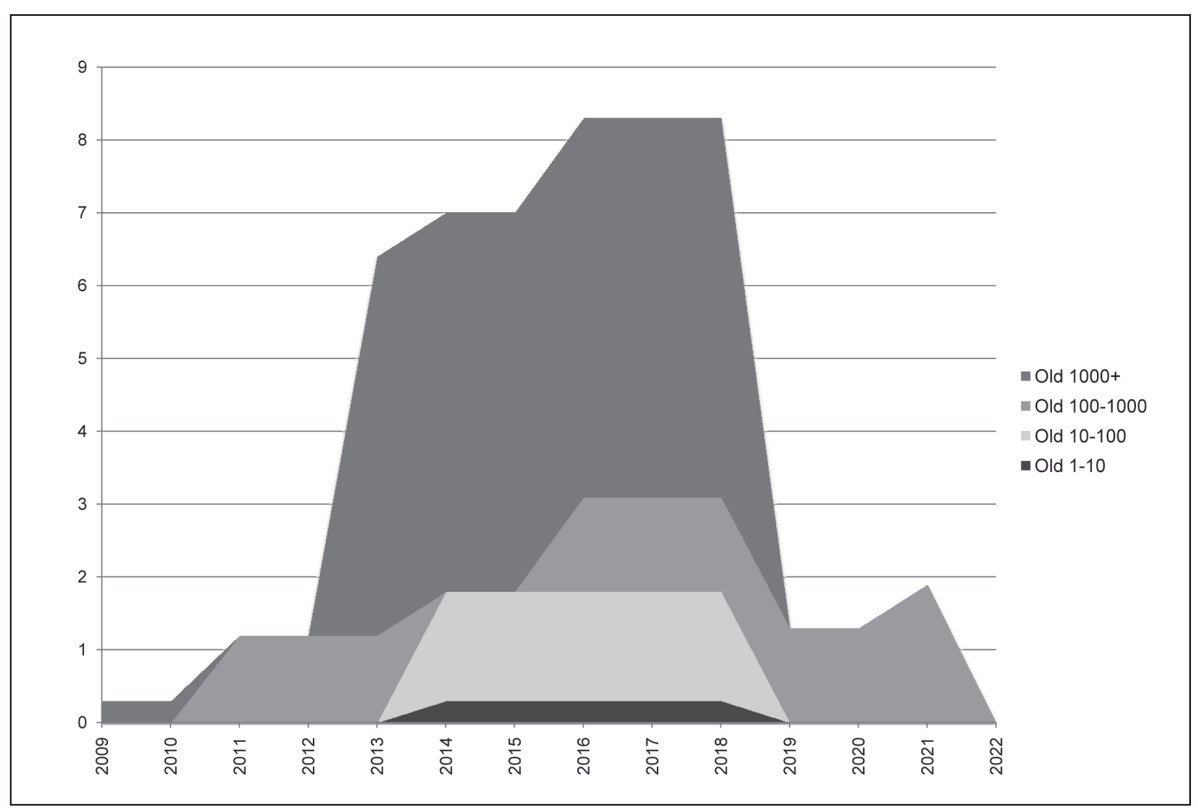

Fig. 4: Animal use in million per year for REACH

The timelines of Figure 2 from 2009 to 2022 and the animal numbers of Figure 3 were combined assuming an equal spread over the years of testing for the different classes of chemicals. Animal numbers are given as million per year. 
points about what to test next based on the first results or results of various measurements can feed into one data analysis generating the overall result. REACH is the forerunner of this, and it is a pity that other newer regulations, such as those on biocides, do not start from the same point.

\section{Consideration 5: Identify the good boys}

Again the mantra... The majority of industrial chemicals are not toxic (Hoffmann and Hartung, 2005; Hartung, 2009a). Thus we need tests that allow them to pass. Developing alternatives for the identification of certain hazards will filter only a few substances, if we cannot rely on the identification of negatives as well. The absence of evidence (of an effect) is not evidence of absence (of the effect). This holds true for the animal tests as well. I am concerned by how often a hazard is masked in vivo, for example, by protective metabolism not present in humans (Hartung, 2008a) or a target structure not present in the animal. The only reasonable approach to overcome this dilemma is represented by the Toxicology in the $21^{\text {st }}$ Century (Tox-21c) concept (NRC, 2007; Blaauboer and Andersen, 2007; Collins et al., 2008; Hartung and Leist, 2008; Leist et al., 2008; Kavlok et al., 2009) to comprehensively map the pathways of toxicity, test whether a substance triggers them, and, if it doesn't, consider it very unlikely that the substance poses a hazard. There are 50 ways to leave your lover, and there are more ways to kill a cell or harm an organism - but not an infinite number of such pathways.

What we need is a pathway definition, a pathway annotation scheme, and a central depository of the annotated pathways. Methods to identify pathways and their targets need to be identified and evaluated. The big challenge will be to use orthogonal methods; for example, combining pathways identified as leading to clinical manifestations by gene polymorphisms with results of toxins identified in omics approaches. Gene silencing, species comparisons, and the like will help to identify them further, as will our knowledge of physiological and biochemical interactions of genes, their proteins, and their metabolites. And these are only the first steps down the road, which continues via definition of test strategies, quality assurance, validation, international harmonization, objective analysis of current practices by evidence-based toxicology, etc. (Hoffmann and Hartung, 2006; Hartung 2007a, 2009b,c; Griesinger et al., 2009). Tox$21 \mathrm{c}$ is moving the discussion in this direction, but it has not been sufficiently acknowledged that Tox-21c is the answer to some of the major challenges posed by REACH. The fact that Tox-21c was prompted by the anticipation of the reauthorization of the Toxic Substance Control Act (TSCA), which is likely to become the US equivalent to REACH, should have made this more obvious. The call for action is getting louder (Collins et al., 2008; Hartung, 2008c; Seidle and Stephens, 2009; Hartung and Daston, 2009; Kavlok et al., 2009; Hartung, 2010). We have already formed an informal implementation group for Tox-21c, organized by CAAT, to promote the various activities (the $3^{\text {rd }}$ meeting is planned as a satellite to the SOT conference in March 2010). However, we will need to transform the group into a consortium to take action. The $€ 50$ million project initiated by European cosmetic industry for novel approaches to systemic toxicity has the chance to form a nucleus for such developments.

\section{Consideration 6: REACH and cosmetics regulation}

The interactions between chemical and cosmetics regulations are not fully clarified (Hartung, 2008b). REACH states clearly that the provisions of the $7^{\text {th }}$ amendment are not affected by the legislation:

(Recital 13): This Regulation should apply without prejudice to the prohibitions and restrictions laid down in Council Directive 76/768/EEC of 27 July 1976 on the approximation of the laws of the Member States relating to cosmetic products in so far as substances are used and marketed as cosmetic ingredients and

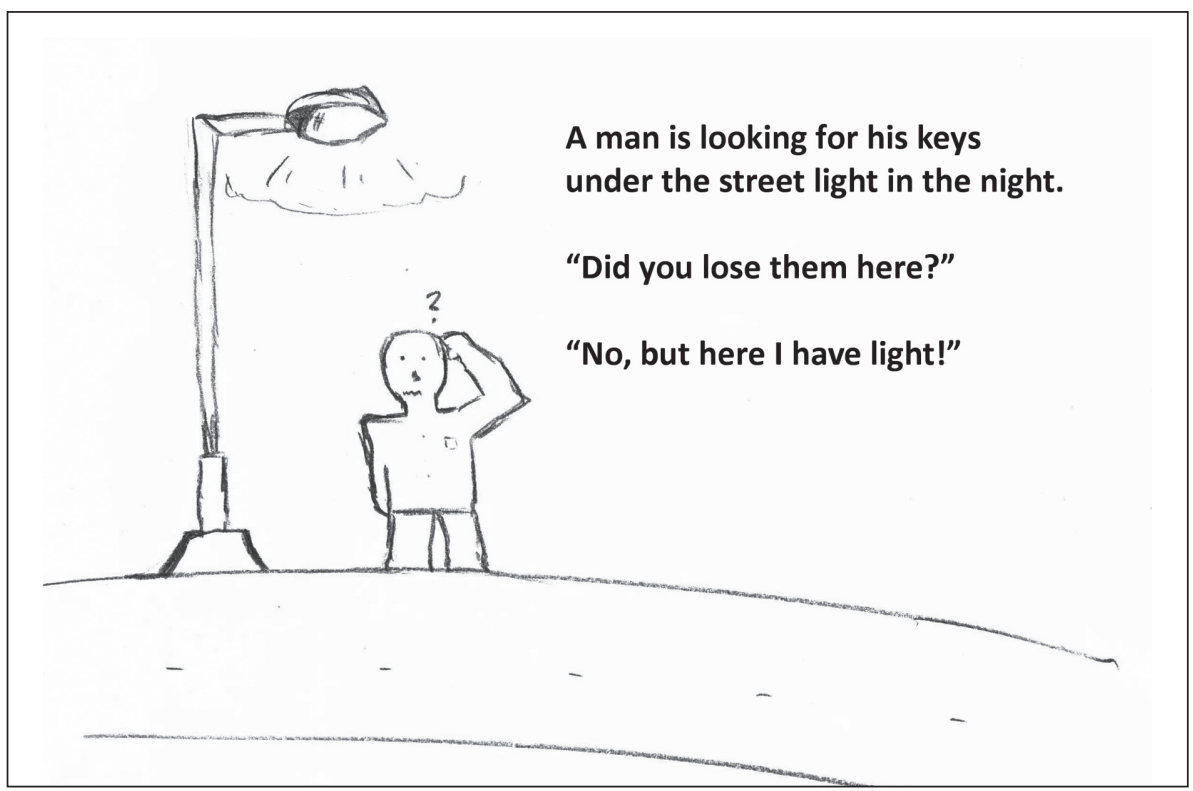

Fig. 5: A common joke to illustrate the fact that we are often guided by the availability of tools and not by the result we are seeking. 
are within the scope of this Regulation. A phase-out of testing on vertebrate animals for the purpose of protecting human health as specified in Directive 76/768/EEC should take place with regard to the uses of those substances in cosmetics.

This is a very clear statement. However, the situation is not as clear if we go into the details, i.e. Article 2.6 only exempts cosmetics from supply chain information, not from testing, and Article $14.5 \mathrm{~b}$ exempts cosmetics from risk assessment (Chemical Safety Report). Notably, there is no exemption from testing. This means that test requirements also apply to cosmetic ingredients, certainly for ingredients used in non-cosmetic products as well. This might be interpreted as opening up testing for these substances again, though not for the purpose of the cosmetics legislation. For chemicals already in use in cosmetics, it is rather unlikely that REACH test requirements will affect their continuing use in cosmetics. For new chemicals, the REACH obligations for testing have to be fulfilled when used in cosmetics. The interesting gap, however, is that test demands for the most relevant 1-10 tonnage range are so limited that they do not suffice for a traditional cosmetic risk assessment, and additional tests would not be covered by the demands of REACH (Hartung, 2008b). This calls for innovative ways to perform risk assessments based on limited in vivo data and the cosmetic legislation might once again become an engine of progress (Hartung, 2008b).

\section{Consideration 7: There is not only REACH}

The problem of toxicological ignorance regarding old chemicals is recognized throughout industrialized countries. Beside TSCA reauthorization, there are similar discussions in Canada, Japan, California, and other countries. REACH is first in class (only in regards to its timing). The approaches in Canada to prioritize substances (with the risk of missing unknown dangerous agents) or in the US to develop new test strategies before testing (with the risk of long delays for development and validation) have their pros and cons. They will have it easier, since they will learn from REACH and benefit from the lessons and data it generates.

Many other business sectors would benefit from the REACH discussions to complement traditional approaches, to challenge them, and to renovate them. A $€ 10$ billion or more exercise should provide good instruction for other industrial areas. Food (Hartung and Koëter, 2008), pesticides, drugs, nanomaterials, childhood hazards, and others should actively take advantage of the lessons learned from REACH. This program is unprecedented, and it is clear that learning needs to take place "on the job". This is not at all bad. Its primary goals are more than warranted. It cannot be expected that a political process can anticipate how science will move, but the process has initiated that movement... into the $21^{\text {st }}$ century.

\section{References}

Blaauboer, B. J. and Andersen, M. E. (2007). The need for a new toxicity testing and risk analysis paradigm to implement REACH or any other large scale testing initiative. Arch. Toxicol. 81, 385-387.
Bottini, A. A. and Hartung, T. (2009). Food for thought ... on economics of animal testing. ALTEX 26, 3-16.

Collins, F. S., Gray, G. M. and Bucher, J. R. (2008). Toxicology: Transforming environmental health protection. Science 319, 906-907.

European Commission (2003). Presence of persistent chemicals in the human body results of Commissioner Wallstrom's blood test. http://europa.eu/rapid/pressReleasesAction.do? reference $=$ MEMO/03/219\&format=HTML\&aged=1\&langua ge $=\mathrm{EN} \&$ guiLanguage $=\mathrm{en}$

Gilbert, N. (2010). Streamlined chemical tests rebuffed. Nature $463,142-143$.

Greim, H., Arand, M., Autrup, H. et al. (2006). Toxicological comments to the discussion about REACH. Arch. Toxicol. 80, 121-124

Griesinger, C., Hoffmann, S., Kinsner-Ovaskainen, A. et al. (2009). Proceedings of the First International Forum Towards Evidence-Based Toxicology. Conference Centre Spazio Villa Erba, Como, Italy. 15-18 October 2007. Human Exp. Toxicol., Special Issue: Evidence-Based Toxicology (EBT) 28, 81-163.

Hareng, L., Pellizzer, C., Bremer, S. et al.(2005). The Integrated Project ReProTect: a novel approach in reproductive toxicity hazard assessment. Reprod. Toxicol. 20, 441-452.

Hartung, T. (2010). Lessons learned from alternative methods and their validation for a new toxicology in the 21 st century. J. Toxicol. Environ. Health, in press.

Hartung, T. (2009a). Toxicology for the twenty-first century. Nature 460, 208-212.

Hartung, T. (2009b). A toxicology for the 21st century: Mapping the road ahead. Tox. Sci. 109, 18-23.

Hartung, T. (2009c). Food for thought ... on evidence-based toxicology. ALTEX 26, 75-82.

Hartung, T. and Daston, G. (2009). Are in vitro tests suitable for regulatory use? Tox. Sci. 111, 233-237.

Hartung, T. and Hoffmann, S. (2009). Food for thought on ... in silico methods in toxicology. ALTEX 26, 155-166.

Hartung, T. and Rovida, C. (2009a). Chemical regulators have overreached. Nature 460, 1080-1081.

Hartung, T. and Rovida, C. (2009b). That which must not, can not be... a reply to the EChA and EDF responses to the REACH analysis of animal use and costs. ALTEX 26, 301305.

Hartung, T. (2008a). Food for thought ... on animal tests. $A L$ TEX 25, 3-9.

Hartung, T. (2008b). Food for thought ... on alternative methods for cosmetics safety testing. ALTEX 25, 147-162.

Hartung, T. (2008c). Towards a new toxicology - evolution or revolution? ATLA 36, 635-639.

Hartung, T. and Leist, M. (2008). Food for thought ... on the evolution of toxicology and phasing out of animal testing. ALTEX 25, 91-96.

Hartung, T. and Koëter, H. (2008). Food for thought ... on alternative methods for food safety testing. ALTEX 25, 259-264.

Hartung, T. (2007a). Food for thought ... on validation. ALTEX $24,67-72$.

Hartung, T. (2007b). Food for thought ... on cell culture. $A L$ TEX 24, 143-147. 
Hoffmann, S. and Hartung, T. (2006). Towards an evidencebased toxicology. Human Exp. Toxicol. 25, 497-513.

Hoffmann, S. and Hartung, T. (2005). Diagnosis: Toxic! - Trying to apply approaches of clinical diagnostics and prevalence in toxicology considerations. Tox. Sci. 85, 422-428.

Johnson, S. R. (2008). The trouble with QSAR (or how I learned to stop worrying and embrace fallacy). J. Chem. Inf. Model. 48, 25-26.

Kavlock, R. J., Austin, C. P. and Tice, R. R. (2009). Commentary - Toxicity testing in the 21 st century: Implications for human health risk assessment. Risk Analysis 29, 485-487.

Kroes, R., Kleiner, J. and Renwick, A. (2005). The threshold of toxicological concern concept in risk assessment. Toxicol. Sci. 86, 226-230.

Leist, M., Hartung, T. and Nicotera, P. (2008). The dawning of a new age of toxicology. ALTEX 25, 103-114.

Maggiora, G. M. (2006). On outliers and activity cliffs - why QSAR often disappoints. J. Chem. Inf. Model. 46, 1535.

Maxim, L. D. and McConnell, E. E. (2001). Interspecies comparisons of the toxicity of asbestos and synthetic vitreous fibers: a weight-of-the-evidence approach. Regul. Toxicol. Pharmacol. 33, 319-342.

Munro, I. R., Renwick, A. G. and Danielewska-Nikiela, B. (2008). The threshold of toxicological concern (TTC) in risk assessment. Toxicol. Lett. 180, 151-156.

NRC (2007). Committee on Toxicity Testing and Assessment of Environmental Agents, National Research Council: Toxicity testing in the 21st century: A vision and a strategy (pp 196). New York: The National Academies Press.

Parzefall, W. (2008). Minireview on the toxicity of dietary acrylamide. Food Chem. Toxicol. 46, 1360-1364.

Rovida, C. and Hartung, T. (2009). Re-evaluation of animal numbers and costs for in vivo tests to accomplish REACH legislation requirements for chemicals. ALTEX 26, 187-208.
Schneider, K., Schwarz, M., Burkholder, I., Kopp-Schneider, A., Edler, L., Kinsner-Ovaskainen, A., Hartung. T. and Hoffmann, S. (2009). "ToxRTool", a new tool to assess the reliability of toxicological data. Toxicol. Lett. 189,138-144.

Seidle, T. and Stephens, M. L. (2009). Bringing toxicology into the 21st century: A global call to action. Toxicol. In Vitro 23, 1576-1579.

Selikoff, I. J. (1990). Historical developments and perspectives in inorganic fiber toxicity in man. Environ. Health Perspect. 88, 269-276.

Shipp, A., Lawrence, G., Gentry, R. et al. (2006). Acrylamide: review of toxicity data and dose-response analyses for cancer and noncancer effects. Crit. Rev. Toxicol. 36, 481-608.

Silbergeld, E. K. (2004). Commentary: the role of toxicology in prevention and precaution. Int. J. of Occupational Medicine and Environmental Health 17, 91-102

Skarabnek, P. and McCormick, J. (1998). Follies and fallacies in medicine. 3rd edition ( $\mathrm{pp}$ 171). Whithorn: Tarragon Press.

\section{Acknowledgement}

The most valuable comments of colleagues and friends, especially Dr. Costanza Rovida, are gratefully appreciated. The design for Figure 5 by Mark Gebel is gratefully appreciated.

\section{Correspondence to}

Prof. Thomas Hartung, MD, PhD

Johns Hopkins University

Bloomberg School of Public Health

Doerenkamp-Zbinden Chair for Evidence-based Toxicology

Center for Alternatives to Animal Testing (CAAT)

615 N. Wolfe St. W7035

Baltimore, MD, 21205, USA

e-mail: Thartung@jhsph.edu

\section{Box 1 \\ Excerpt of the most relevant parts of the REACH regulation for alternatives to animal use}

(http://echa.europa.eu/legislation/reach_legislation_en.asp)

(Recital 1) This Regulation should also promote the development of alternative methods for the assessment of hazards of substances.

(Recital 38) The generation of information by alternative means offering equivalence to prescribed tests and test methods should also be allowed, for example when this information comes from valid qualitative or quantitative structure activity models or from structurally related substances.

(Recital 40) The Commission, Member States, industry and other stakeholders should continue to contribute to the promotion of alternative test methods on an international and national level including computer supported methodologies, in vitro methodologies, such as appropriate, those based on toxicogenomics, and other relevant methodologies. The Community's strategy to promote alternative test methods is a priority and the Commission should ensure that within its future Research Framework Programmes and initiatives such as the Community Action Plan on the Protection and Welfare of Animals 2006-2010 this remains a priority topic. Participation of stakeholders and initiatives involving all interested parties should be sought.

(Recital 47) In accordance with Directive 86/609/EEC, it is necessary to replace, reduce or refine testing on vertebrate animals. Implementation of this Regulation should be based on the use of alternative test methods, suitable for the assessment of health and environmental hazards of chemicals, wherever possible. The use of animals should be avoided by recourse to 
alternative methods validated by the Commission or international bodies, or recognised by the Commission or the Agency as appropriate to meet the information requirements under this Regulation. To this end, the Commission, following consultation with relevant stakeholders, should propose to amend the future Commission Regulation on test methods or this Regulation, where appropriate, to replace, reduce or refine animal testing. The Commission and the Agency should ensure that reduction of animal testing is a key consideration in the development and maintenance of guidance for stakeholders and in the Agency's own procedures.

\section{Article 1 Aim and scope}

1. The purpose of this Regulation is to ensure a high level of protection of human health and the environment, including the promotion of alternative methods for assessment of hazards of substances, as well as the free circulation of substances on the internal market while enhancing competitiveness and innovation.

Article 13 General requirements for generation of information on intrinsic properties of substances

1. Information on intrinsic properties of substances may be generated by means other than tests, provided that the conditions set out in Annex XI are met. In particular for human toxicity, information shall be generated whenever possible by means other than vertebrate animal tests, through the use of alternative methods, for example, in vitro methods or qualitative or quantitative structure-activity relationship models or from information from structurally related substances (grouping or read-across). Testing in accordance with Annex VIII, section 8.6 and 8.7, Annex IX and Annex X may be omitted where justified by information on exposure and implemented risk management measures as specified in Annex XI, section 3.

2. These methods shall be regularly reviewed and improved

\section{ANNEX I}

GENERAL PROVISIONS FOR ASSESSING SUBSTANCES AND PREPARING CHEMICAL SAFETY REPORTS

0.12. Where the methodology described in this Annex is not appropriate, details of alternative methodology used shall be explained and justified in the chemical safety report.

\section{ANNEX VI}

\section{INFORMATION REQUIREMENTS REFERRED TO}

IN ARTICLE 10

GUIDANCE NOTE ON FULFILLING THE

REQUIREMENTS OF ANNEXES VI TO XI

\section{STEP 1 - GATHER AND SHARE EXISTING INFORMATION}

The registrant should gather all existing available test data on the substance to be registered, this would include a literature with a view to reducing testing on vertebrate animals and the number of animals involved. The Commission, following consultation with relevant stakeholders, shall, as soon as possible, make a proposal, if appropriate, to amend the Commission Regulation on test methods adopted in accordance with the procedure referred to in Article 133(4), and the Annexes of this Regulation, if relevant, so as to replace, reduce or refine animal testing. Amendments to that Commission Regulation shall be adopted in accordance with the procedure specified in paragraph 3 and amendments to the Annexes of this Regulation shall be adopted in accordance with the procedure referred to in Article 131.

\section{Article 117 Reporting}

4. Every five years, the Commission shall publish a general report on...

(b) the amount and distribution of funding made available by the Commission for the development and evaluation of alternative test methods.

The first report shall be published by 1 June 2012 .

\section{Article 138 Review}

3. The report, referred to in Article 117(4), on the experience acquired with the operation of this Regulation shall include a review of the requirements relating to registration of substances manufactured or imported only in quantities starting at 1 tonne but less than 10 tonnes per year per manufacturer or importer. On the basis of that review, the Commission may present legislative proposals to modify the information requirements for substances manufactured or imported in quantities of 1 tonne or more up to 10 tonnes per year per manufacturer or importer, taking into account the latest developments, for example in relation to alternative testing and (quantitative) structure-activity relationships ((Q)SARs).

search for relevant information on the substance. Wherever practicable, registrations should be submitted jointly, in accordance with Articles 11 or 19 . This will enable test data to be shared, thereby avoiding unnecessary testing and reducing costs. The registrant should also collect all other available and relevant information on the substance regardless whether testing for a given endpoint is required or not at the specific tonnage level. This should include information from alternative sources (e.g. from (Q)SARs, read-across from other substances, in vivo and in vitro testing, epidemiological data) which may assist in identifying the presence or absence of hazardous properties of the substance and which can in certain cases replace the results of animal tests.

\section{... \\ STEP 4 - GENERATE NEW DATA/PROPOSE TESTING STRATEGY}

In some cases it will not be necessary to generate new data. However, where there is an information gap that needs to be 
filled, new data shall be generated (Annexes VII and VIII), or a testing strategy shall be proposed (Annexes IX and X), depending on the tonnage. New tests on vertebrates shall only be conducted or proposed as a last resort when all other data sources have been exhausted.

In some cases, the rules set out in Annexes VII to XI may require certain tests to be undertaken earlier than or in addition to the standard requirements.

\section{ANNEX XI}

GENERAL RULES FOR ADAPTATION OF THE STANDARD TESTING REGIME

\section{SET OUT IN ANNEXES VII TO $\mathrm{X}$}

Annexes VII to X set out the information requirements for all substances manufactured or imported

in quantities of:

- 1 tonne or more in accordance with Article 12(1)(a),

- 10 tonnes or more in accordance with Article 12(1)(c),

- 100 tonnes or more in accordance with Article 12(1)(d), and

- 1,000 tonnes or more in accordance with Article 12(1)(e).

In addition to the specific rules set out in Column 2 of Annexes VII to X, a registrant may adapt the standard testing regime in accordance with the general rules set out in Section 1 of this Annex.

Under dossier evaluation the Agency may assess these adaptations to the standard testing regime.

\section{TESTING DOES NOT APPEAR SCIENTIFICALLY NECESSARY}

1.1. Use of existing data

1.1.1. Data on physical-chemical properties from experiments not carried out according to GLP

or the test methods referred to in Article 13(3)

Data shall be considered to be equivalent to data generated by the corresponding test methods referred to in Article 13(3) if the following conditions are met:

1) adequacy for the purpose of classification and labelling and/ or risk assessment;

2) sufficient documentation is provided to assess the adequacy of the study; and

3 ) the data are valid for the endpoint being investigated and the study is performed using an acceptable level of quality assurance.

1.1.2. Data on human health and environmental properties from experiments not carried out according to GLP or the test methods referred to in Article 13(3)

Data shall be considered to be equivalent to data generated by the corresponding test methods referred to in Article 13(3) if the following conditions are met:

1) adequacy for the purpose of classification and labelling and/ or risk assessment;

2) adequate and reliable coverage of the key parameters foreseen to be investigated in the corresponding test methods referred to in Article 13(3);
3) exposure duration comparable to or longer than the corresponding test methods referred to in Article 13(3) if exposure duration is a relevant parameter; and

4) adequate and reliable documentation of the study is provided.

\subsubsection{Historical human data}

Historical human data, such as epidemiological studies on exposed populations, accidental or occupational exposure data and clinical studies, shall be considered.

The strength of the data for a specific human health effect depends, among other things, on the type of analysis and on the parameters covered and on the magnitude and specificity of the response and consequently the predictability of the effect. Criteria for assessing the adequacy of the data include:

1) the proper selection and characterisation of the exposed and control groups;

2) adequate characterisation of exposure;

3) sufficient length of follow-up for disease occurrence;

4) valid method for observing an effect;

5) proper consideration of bias and confounding factors; and

6) a reasonable statistical reliability to justify the conclusion.

In all cases adequate and reliable documentation shall be provided.

\subsection{Weight of evidence}

There may be sufficient weight of evidence from several independent sources of information leading to the assumption/conclusion that a substance has or has not a particular dangerous property, while the information from each single source alone is regarded insufficient to support this notion.

There may be sufficient weight of evidence from the use of newly developed test methods, not yet included in the test methods referred to in Article 13(3) or from an international test method recognised by the Commission or the Agency as being equivalent, leading to the conclusion that a substance has or has not a particular dangerous property.

Where sufficient weight of evidence for the presence or absence of a particular dangerous property is available:

- further testing on vertebrate animals for that property shall be omitted,

- further testing not involving vertebrate animals may be omitted. In all cases adequate and reliable documentation shall be provided.

1.3. Qualitative or Quantitative structure-activity relationship ((Q)SAR)

Results obtained from valid qualitative or quantitative structure-activity relationship models ((Q)SARs) may indicate the presence or absence of a certain dangerous property. Results of (Q)SARs may be used instead of testing when the following conditions are met:

- results are derived from a (Q)SAR model whose scientific validity has been established,

- the substance falls within the applicability domain of the (Q) SAR model, 
- results are adequate for the purpose of classification and labelling and/or risk assessment, and

- adequate and reliable documentation of the applied method is provided.

The Agency in collaboration with the Commission, Member States and interested parties shall develop and provide guidance in assessing which (Q)SARs will meet these conditions and provide examples.

\subsection{In vitro methods}

Results obtained from suitable in vitro methods may indicate the presence of a certain dangerous property or may be important in relation to a mechanistic understanding, which may be important for the assessment. In this context, "suitable" means sufficiently well developed according to internationally agreed test development criteria (e.g. the European Centre for the Validation of Alternative Methods (ECVAM)) criteria for the entry of a test into the prevalidation process). Depending on the potential risk, immediate confirmation requiring testing beyond the information foreseen in Annexes VII or VIII or proposed confirmation requiring testing beyond the information foreseen in Annexes IX or X for the respective tonnage level may be necessary.

If the results obtained from the use of such in vitro methods do not indicate a certain dangerous property, the relevant test shall nevertheless be carried out at the appropriate tonnage level to confirm the negative result, unless testing is not required in accordance with Annexes VII to X or the other rules in this Annex.

Such confirmation may be waived, if the following conditions are met:

1) results are derived from an in vitro method whose scientific validity has been established by a validation study, according to internationally agreed validation principles;

2) results are adequate for the purpose of classification and labelling and/or risk assessment; and

3) adequate and reliable documentation of the applied method is provided.

\subsection{Grouping of substances and read-across approach}

Substances whose physicochemical, toxicological and ecotoxicological properties are likely to be similar or follow a regular pattern as a result of structural similarity may be considered as a group, or "category" of substances. Application of the group concept requires that physicochemical properties, human health effects and environmental effects or environmental fate may be predicted from data for reference substance(s) within the group by interpolation to other substances in the group (readacross approach). This avoids the need to test every substance for every endpoint. The Agency, after consulting with relevant stakeholders and other interested parties, shall issue guidance on technically and scientifically justified methodology for the grouping of substances sufficiently in advance of the first registration deadline for phase-in substances.

The similarities may be based on:

1) a common functional group;

2) the common precursors and/or the likelihood of common breakdown products via physical and biological processes, which result in structurally similar chemicals; or

3) a constant pattern in the changing of the potency of the properties across the category.

If the group concept is applied, substances shall be classified and labelled on this basis. In all cases results should:

- be adequate for the purpose of classification and labelling and/ or risk assessment,

- have adequate and reliable coverage of the key parameters addressed in the corresponding test method referred to in Article 13(3),

- cover an exposure duration comparable to or longer than the corresponding test method referred to in Article 13(3) if exposure duration is a relevant parameter, and

- adequate and reliable documentation of the applied method shall be provided.

\section{TESTING IS TECHNICALLY NOT POSSIBLE}

Testing for a specific endpoint may be omitted, if it is technically not possible to conduct the study as a consequence of the properties of the substance: e.g. very volatile, highly reactive or unstable substances cannot be used, mixing of the substance with water may cause danger of fire or explosion or the radiolabelling of the substance required in certain studies may not be possible. The guidance given in the test methods referred to in Article 13(3), more specifically on the technical limitations of a specific method, shall always be respected.

\section{SUBSTANCE-TAILORED EXPOSURE-DRIVEN TESTING}

3.1. Testing in accordance with sections 8.6 and 8.7 of Annex VIII, Annex IX and Annex X may be omitted, based on the exposure scenario(s) developed in the Chemical Safety Report.

3.2. In all cases, adequate justification and documentation shall be provided. The justification shall be based on an exposure assessment in accordance with section 5 of Annex I and be consistent with the criteria adopted pursuant to section 3.3 , and the specific conditions of use must be communicated through the chemical supply chain in accordance with Articles 31 or 32 .

3.3. The Commission shall adopt the measures designed to amend non-essential elements of this Regulation by supplementing it, in accordance with the procedure referred to in Article $133(4)$, to set the criteria defining what constitutes adequate justification under Section 3.2 by 1 December 2008 . 